\title{
Article \\ Improvements and Operational Application of a Zero-Order Quick Assessment Model for Flood Damage: A Case Study in Italy
}

\author{
Luca Manselli ${ }^{1}$, Daniela Molinari ${ }^{2} \mathbb{D}$, Arianna Pogliani ${ }^{2} \mathbb{D}$, Federica Zambrini ${ }^{2, * \mathbb{D}}$ and Giovanni Menduni ${ }^{2} \mathbb{D}$ \\ 1 Italian National Fire Corps, Provincial Command of Ravenna, Viale Vincenzo Randi 25, 48121 Ravenna, Italy; \\ luca.manselli@vigilfuoco.it \\ 2 Department of Civil and Environmental Engineering, Politecnico di Milano, Piazza Leonardo da Vinci 32, \\ 20133 Milan, Italy; daniela.molinari@polimi.it (D.M.); arianna.pogliani@polimi.it (A.P.); \\ giovanni.menduni@polimi.it (G.M.) \\ * Correspondence: federica.zambrini@polimi.it
}

Citation: Manselli, L.; Molinari, D.; Pogliani, A.; Zambrini, F.; Menduni, G. Improvements and Operational Application of a Zero-Order Quick Assessment Model for Flood Damage: A Case Study in Italy. Water 2022, 14, 373. https://doi.org/10.3390/ w14030373

Academic Editor: Chang Huang

Received: 29 November 2021

Accepted: 21 January 2022

Published: 26 January 2022

Publisher's Note: MDPI stays neutral with regard to jurisdictional claims in published maps and institutional affiliations.

Copyright: (C) 2022 by the authors. Licensee MDPI, Basel, Switzerland. This article is an open access article distributed under the terms and conditions of the Creative Commons Attribution (CC BY) license (https:// creativecommons.org/licenses/by/ $4.0 /)$

\begin{abstract}
Flood damage assessment is an essential asset in flood risk management, and the literature brings several models, most based on damage curves. This kind of approach is essential and well established but not suitable for being applied in the immediate aftermaths of a flood. Herein, a new application of a zero-order model for the Po-Venetian plain area, which covers more than $20 \%$ of the Italian territory, is conceived and implemented. At first, a calibration of the model with damage data coming from past events in the region is carried out, showing that the calibration is site-specific. In particular, it is shown how the exponent in the power-law form of the model is the same as obtained in a previous work on another territory, while the intercept, defined as specific damage, varies. Then the algorithm is applied to the area affected during the flood that hit the Emilia-Romagna region (Northern Italy), in December 2020, for validation. Knowledge of the affected area comes from the quick assessment procedure commonly performed by the National Fire Corps in any significant flood, employing low-altitude all-weather helicopter GPS surveys. The paper shows that combining the model with such a rapid mapping technique leads to a near real-time estimation of damages in the aftermath of floods. The results are aimed at obtaining a first approximation figure. The estimation error shows this figure to be not far from those obtained with much more detailed approaches, requiring a much longer time for their setting. For that reason, the model results can contribute, among other things, by directing the immediate post-emergency management operations and promptly allocating financial resources for recovery.
\end{abstract}

Keywords: floods; damage; rapid mapping; Fire Corps surveys; damage estimation

\section{Introduction}

In the last decades, damage assessment has gained an essential role in the chain of flood risk evaluation. An assessment of expected damage is crucial in situations where structural or non-structural interventions are necessary to reduce the natural risk [1]. At the same time, rapid damage appraisal in the aftermath of floods is fundamental to support emergency management and address resources by identifying intervention priorities [2]. Flood damage data represent an essential source of knowledge for the scientific community to understand damage mechanisms and develop damage models [3]. Since flooding represented the third major cause of economic loss worldwide [4] between 2006 and 2015, European countries started to improve their damage data collection systems and damage modeling [5].

In Italy, since 2013, data are collected for the most intense events and are based on the self-declaration of citizens [6]. Forms filled in by citizens represent good pieces of information to analyze damage mechanisms, but they keep a subjective part on damage 
estimation that is impossible to be removed (such as the level of maintenance of the damaged buildings). The archive, however, is still neither complete and uniform nor available in an easy way. We managed to collect a good portion of this data, with a dataset that is continuously in development and being updated.

Moreover, a significant effort has been made in the last decades to formulate models to estimate flood damage [7,8]. Numerous tools are now available to estimate the damage to the different assets exposed to flood. Assessing the damage may refer to expected annual damage in the whole or in the damage itself, which can include or not the intangible and indirect components [9], as well as being expressed in economic or financial units [10]. Here, we refer to the only estimation of direct damages to the private property in financial terms. The typical approach to deal with such a theme is based on the formulation of a model that relates to the simulation of the whole hydrologic cycle: a first step requires the model of hydrologic events producing a certain distribution of hydrologic variables (such as water depth, water velocity, and pollution) [11-13] in the affected area that, again, can be identified running the model. In the second step, the relation between such variables and the damage itself is determined. Roughly, it can be stated that the main physical variable is the water depth $[14,15]$, to be put in relation with the available information on the urban assets (type, material, and maintenance of buildings) [12] to obtain the wellknown empirical stage-damage curve [16,17]. This kind of approach is very useful and largely adopted; the theoretical amount of data is reduced to small numbers of samples [18]. Some problems may arise for areas with data scarcity and lack of hydraulic modeling, but they have been overcome with approaches such as expert-based methods and expert elicitation [19-21]. However, the implementation in the aftermath of an event remains tricky still as the already mentioned parameters describing the hydrologic development of the flood may take weeks or months to be evaluated [11].

To overcome this problem, and to provide an additional tool suitable to be implemented right after the event, we developed a prototype "zero-order" damage model, which allows a quick estimation of direct flood damage to residential buildings based upon the simple knowledge of the perimeter of the flooded area [22]. Indeed, this piece of information is usually available in the aftermath of the flood by several quick assessment techniques $[23,24]$. This model does not intend to compete with more complex and detailed approaches but is in synergy with them, providing immediate results, otherwise impossible to obtain. It can be seen as a tool suitable for the very first phases of emergency management, to help administrators in prioritizing areas where to concentrate funds and interventions. The aim is not to precisely explain what happened but to provide the order of magnitude on the damage on the whole affected area: it provides the first level of knowledge on the territory, to be empowered and enlarged in the upcoming phases using the other methodologies. However, it is worth noting how the performances are indeed quite similar to the average results of methods that are much more complex. In fact, a previous study that carried out an extensive comparison of different damage models showed that, on average, the error considering the only model developed and calibrated for Italy-the most affordable for the authors-was $46 \%$ [25]. This value can be compared to those that are presented in the conclusion section.

This paper aims to further investigate and demonstrate the effectiveness of the "zeroorder" model, going deep into a specific case history and introducing a quick surveying technique. In particular, we analyze the flood event in Emilia-Romagna, Northern Italy, in early December 2020. The workflow is shown in Figure 1.

We first briefly introduce the case study in Emilia-Romagna and the quick surveying methods in the post-event. We then discuss the implementation of the model, which was possible due to a new calibration and validation performed on a specific homogeneous area (HA) covering most of Northern Italy. The results are then shown, together with the discussion. 


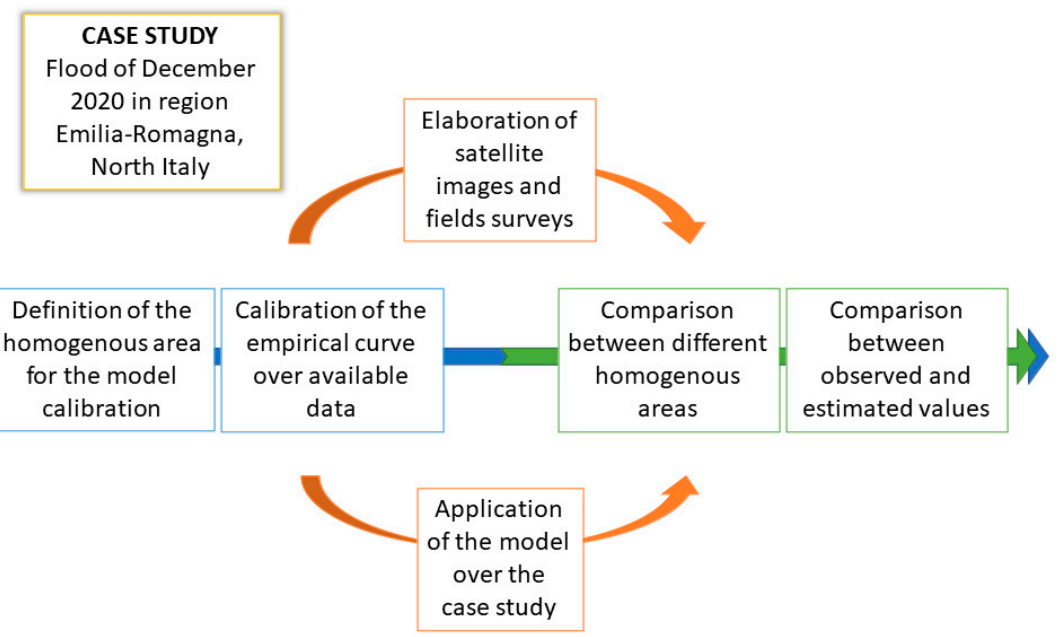

Figure 1. Workflow.

\section{Case Study}

The flood originated from two subsequent events that hit Northern Italy at the end of 2020. In the Emilia-Romagna region, the descent of a deep depression wave caused the irruption of cold air and a sharp drop in temperatures in the first days of December. The polar currents caused abundant snowfalls down to lowland altitudes. From 4th to 8 th December, hot and humid air flows fed intense and persistent rainfall on the whole region, giving rise to several successive thunderstorms, definitely unusual in the winter period in Italy.

The rapid increase in temperatures caused the partial melting of the snow that had fallen in the preceding days. This snowmelt heavily increased the runoff from the Apennine basins, generating floods with sequences of peaks close together on all watercourses [26]. The main focus of the analysis is the Panaro river, which is the last right tributary downstream of the Po River and which flows in the outskirts of the town of Modena (Figure 2).

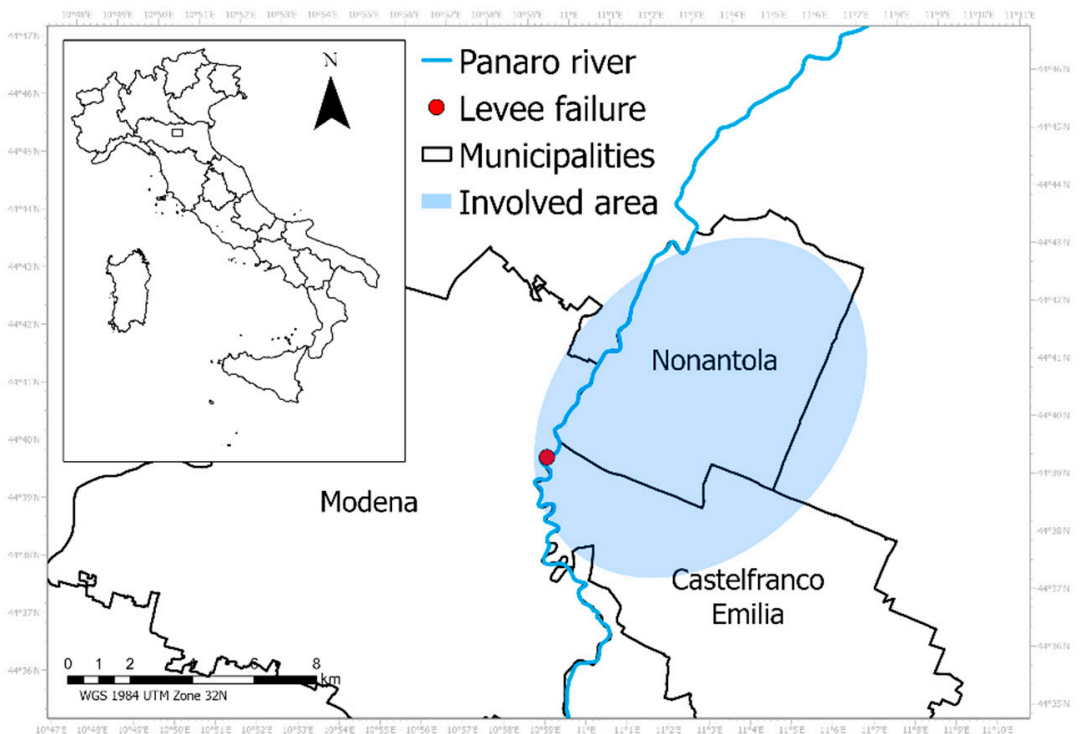

Figure 2. Case study: levee failure in the municipality of Castelfranco Emilia that caused river Panaro flooding.

The flood peak exceeded all historical records in the Panaro river plain sensors, causing a breach in the right bank levee, which occurred on the morning of 6 December by the village called Gaggio. An area of around $15 \mathrm{~km}^{2}$ in Castelfranco Emilia and Nonantola was 
flooded, giving rise to severe damages. The flood then proceeded in a northeast direction during the morning.

The Governor of the Region asked the national Government for the proclamation of a state of emergency (https:/ / www.protezionecivile.gov.it/it/dipartimento/amministrazionetrasparente/interventi-straordinari-e-di-emergenza, last access on 20 January 2022). The state of emergency is the measure through which the Government deals with extraordinary events by allocating an adequate amount of money for the emergency management and teams for rescue intervention and first aid to the population. This enabled the damage self-declarations procedure carried out by citizens. As we can observe in Figure 3, the territory was completely flooded, both in the rural part of the town and in the city center.

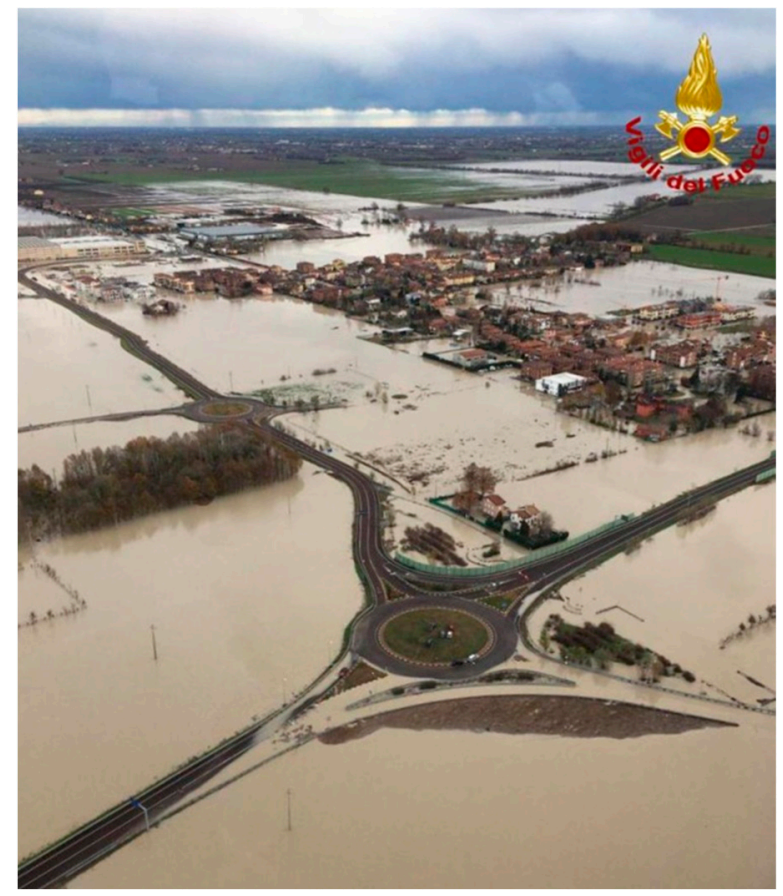

Figure 3. Picture of the flooded area of Nonantola (courtesy of the Italian National Fire Corps).

Moreover, intense activities are carried out over the flooded territories to map the flood's perimeter and take notes of the damages reported by citizens. Indeed, people affected by the flood can ask for economic compensation damages to private houses, public goods, and economic activities by filling in forms collected in the aftermath of the flood, which are then processed and stored by the region [22].

In the specific case under investigation, information regarding the flood extension and local water elevation was quickly collected by different actors in the aftermath of the event. All available data have been integrated with further investigations to obtain the detailed flood mapping necessary to run the zero-order damage model. Moreover, citizens' claims for damage refunds were made available by the Emilia-Romagna Regional Authority. Table 1 shows the number of available data, including both damages to primary dwellings and holiday houses. It is worth noting that they refer only to damages produced by the levee breach. Other minor damages, mainly due to stagnation, were observed in the town of Modena but are not treated in this paper.

Table 1. The available dataset in terms of single claims and observed economic damage.

\begin{tabular}{ccc}
\hline Damaged Properties & Number of Claims & Total Observed Damage \\
\hline Main dwellings & 2394 & EUR 47,5 M \\
Holiday houses & 237 & EUR 4,5 M \\
\hline
\end{tabular}




\section{Materials and Methods}

\subsection{Model}

The "zero-order" damage model is a regression model in the form

$$
D=s F_{a}{ }^{m}
$$

where $D$ is the total damage to residential buildings in the area under investigation, in currency units, $F_{a}$ is the residential flooded area footprint $\left(\mathrm{m}^{2}\right)$, $s$ a "specific damage" parameter denoting the damage (also in currency units) corresponding to the unit surface of buildings, and $m$ an exponent of the power-law 9, derived by the regression analysis. It can be observed that the model allows estimating damage to residential buildings with just a few pieces of information: the only variable requested for damage calculation is indeed the residential flooded area $F_{a}$, which can be obtained by combining national statistical data once the total flooded surface envelope $S_{0}$ is known. "Zero-order" means indeed that the model does not account for the flood water elevation. The dependence of damage on the surface has been proven to be meaningful in many applications [27]. Height is also important but is here neglected in the top-down approach, which needs to be applied within a time window where this piece of information cannot be available.

The model was initially calibrated and validated on a set of 3729 citizens' claims collected after 8 different national emergency states in Southern Italy. Given that significant differences exist between the physical and the socio-economic context of the area under investigation and South Italy [28], the implementation of the model required a new calibration for its application over the case study.

This new application allows us to underline some points on the definition of a homogenous area concept: in fact, here we introduce a new dataset for calibration and validation that, even though it is in Italy, refers to a completely different context. It is important to understand how a homogeneous area can be identified to properly apply the model. How the socio-economic variables, together with the morphologic ones, affect the equation's parameters is still under investigation and will be the topic of the next work.

\subsection{Calibration Area}

The calibration area was defined looking for homogeneity for two factors: the first concerns the morphologic context where the flood occurs, the second deals with the social and economic fabric of the flooded areas. For example, we might consider a lowland environment, characterized by large extensions of flooded areas, relatively low water velocity values, and high residence times; alternatively, we could be facing a more typically mountainous environment, with narrower valleys, high slopes, high flow speeds, high potential momentum exchange with exposed assets, and typically shorter residence times. Regarding social and economic texture, we need to consider, for example, that agricultural zones with a dispersed urban texture are quite different from a typical urban environment with high population, and commercial and infrastructural density [29]. Indeed, the specific damage parameter $s$ accounts for all these aspects, and its rating strongly depends on the spatial scale at which the calibration is performed.

The case study covers a small portion of the Po Valley, which can be considered typical of the physical and socio-economic context of the whole Po-Venetian plain region. The model was then calibrated and validated at the scale of the whole plain.

The Po-Venetian plain is the most extensive floodplain in Italy, covering an area of $42,000 \mathrm{~km}^{2}$ within the Po River watershed. The Po is the longest Italian river with a length of over $650 \mathrm{~km}$; its watershed is $75,000 \mathrm{~km}^{2}$ and covers most of Northern Italy [30]. In the national framework, it represents the highest concentration of inhabitants and economic activities. The plain covers just one-eighth of the national territory and hosts nearly 15 million inhabitants, equal to over a quarter of the Italian population. The demographic density, 355 inhabitants per square kilometers, is almost double the national average. Though agriculture remains a strategic asset in the territory, the importance of economic activities 
emerges even more clearly as we consider on the national scale that $40 \%$ of employees in industry and 33\% of employees in the tertiary sector work in this area [31]. Municipalities in the plain settle mostly at low elevations and in a quite similar morphological context. The built environment [32] follows main road infrastructures and river lines as a nearly continuous sequence, as easily seen in any satellite image of Northern Italy taken at night. The Po Valley, as a whole, is also typically a specific flood-prone area protected by hundreds of kilometers of embankment lines [33]. Disastrous floods mainly occur as a result of the overtopping of the embankments [34] due to breaches caused, e.g., by the action of burrowing animals [35] or seepage and piping problems [36]. Together with the analysis of long records of floods on the Po River [37], these considerations support the assumption that the flood type as damage forcing agent is reasonably uniform on the Po-Venetian plain.

\subsection{Calibration Data}

Damage data are not always made available by regional authorities for research purposes. For this work, we obtained data related to 21 floods that occurred in the latest years in the Po-Venetian area.

Damage claims are available for 406 municipalities that were strongly damaged by some past flood events [22]. Of these municipalities, around $60 \%$ show an average altitude of less than $350 \mathrm{~m}$ a.s.l. We limited the calibration and validation dataset to this subset to be sure to deal with a typical plain environment, such as the one characterizing the case study area. Moreover, municipalities with a few claims (1-2 units) have been excluded as they are less meaningful for the model calibration. The final dataset is then composed of data from 187 municipalities, shown in Figure 4, located in the regions Emilia-Romagna, Lombardia, and Veneto, and corresponding to 7907 single damage claims (i.e., damage to an individual residential building), collected after the declaration of 11 national states of emergency. The total dataset has been divided into two datasets to calibrate and validate the model with a random choice: actually, damage data collected in the same region were used in part for the calibration, in part for the validation phase. In particular, 113 municipalities have been considered for model calibration (corresponding to 4453 damage claims), while 74 municipalities for validation (3454 claims).

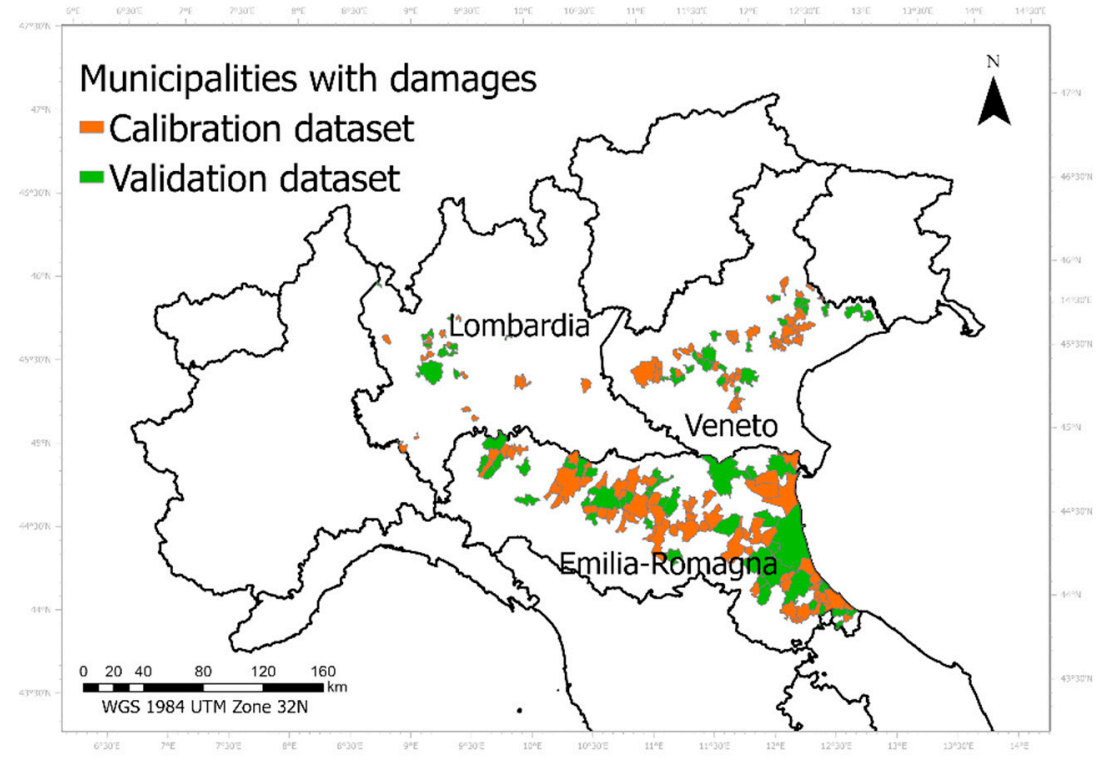

Figure 4. Municipalities considered for the model calibration and validation.

\subsection{Definition of the Residential Flooded Area}

As already discussed, the only variable requested by the model for damage assessment is the residential flooded area $F_{a} 9 \mathrm{~m}^{2}$ ). This variable is an indicator of the overall building footprint surface within the event flooded perimeter and can be obtained from national 
statistical data once the total flooded surface envelope $S_{0}$ is known. Indeed, the Italian National Statistics Institute (ISTAT) (http: / / dati.istat.it/, last access on 20 January 2022) provides different data about the housing stock such as surface, number of floors, construction typology, materials, etc. Such data are aggregated at the resolution of the "census areas", polygons from an irregular adaptative mesh covering the whole country (for a total of 402,678 census areas), with an average size of $0.8 \mathrm{~km}^{2}$. The dimension decreases with the increase in the complexity of the urban texture [38]. In an urban environment, the size of a census area can reach that of a single block. Census data were published every ten years after the general national census in 1991, and in this paper, we stick to data published in 2011 since they are the most recent available, and the most suitable to deal with events that occurred after 2013. Indeed, the national statistical system is currently transitioning towards a new "permanent" model with the resolution of the data at the scale of a single building, but data are not available yet. The use of building census data in natural risk reduction policies is not new. For example, it is used for seismic vulnerability distribution assessment at the national scale [39]. We then cropped the census areas mesh (available in the ISTAT national geodatabase) with the total flooded surface $S_{0}$, thus obtaining an estimate of $F_{a}$ by simple GIS operations.

The total flooded area $S_{0}$ was derived by combining several pieces of information. First, we analyzed satellite data. In the aftermath of major floods, delineation of flooded areas is usually performed by multispectral satellite data, SAR (Synthetic Aperture Radar) images, or a combination of both [40]. In our case, the Italian Civil Protection is an authorized user of the Copernicus Emergency Management Service Mapping (CEMS) [23], whose Rapid Mapping service provides on demand a pre-event [41] and three post-event maps of the affected area, for emergencies arising from natural or anthropogenic disasters anywhere in the world. The service was activated $9 \mathrm{~h}$ after the breach had started with the following tag of the Emergency Management Service, Rapid Mapping activation: "EMSR487: Flood in Emilia-Romagna Region, Italy" (Figure 5).

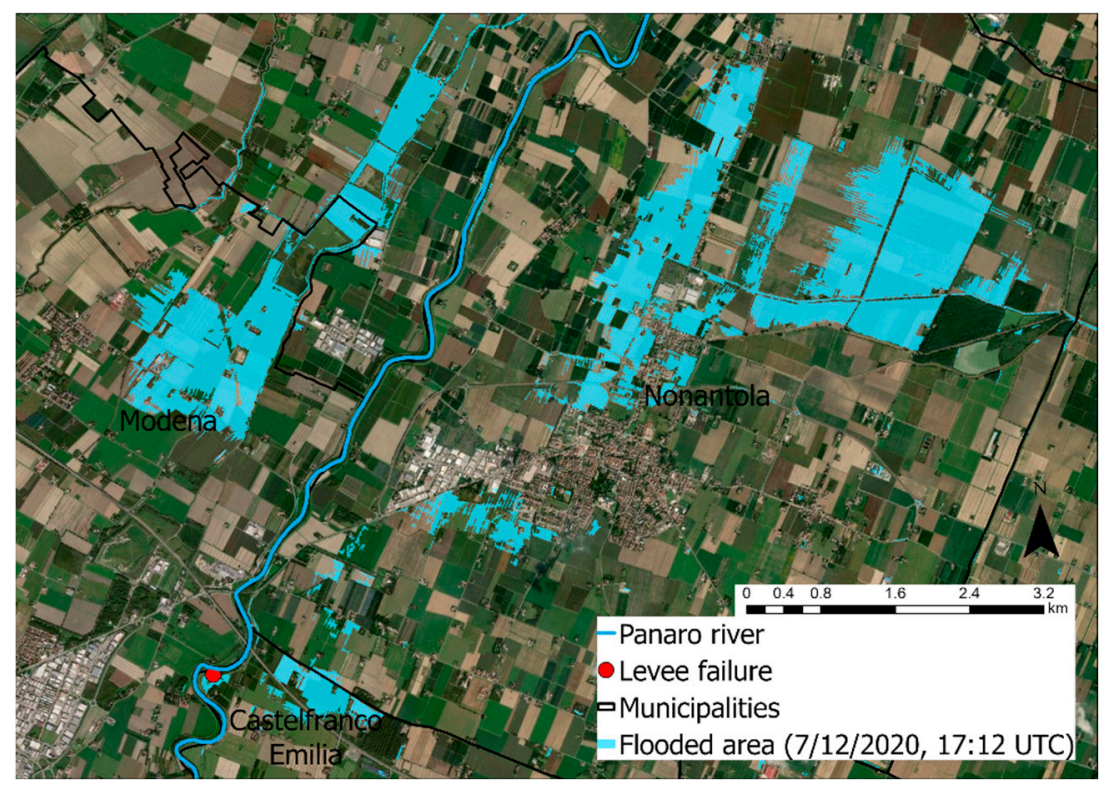

Figure 5. Flooded area on the day after the event (from Copernicus EMS).

In Italy, during 2020, there were 5 CEMS activations due to floods. In the same period, 12 national emergency states were declared by the Government in Italy due to meteorological and hydrological factors (Data from the government site https: / www.protezionecivile. it/it/dipartimento/amministrazione-trasparente/interventi-straordinari-e-di-emergenza/ emergenze-il-rischio-meteo-idro, last access on 20 January 2022). Many of these cases involved multiple flood events. From these data, it is clear that activations only take place on major events for which strategic support is required for the emergency and rescue 
organization. These conditions are not always the case. On the other hand, damage due to hydrogeological emergencies is increasing due to climate change [42], and it is crucial to be able to systematically have a rapid estimate of the damage to understand the intensity of the impact, starting with the assessment of flooded area boundaries.

It should also be remembered that satellite assessments, however accurate, involve approximations due to the delay with which the satellite visits the disaster site, compared to the actual event time. CEMS largely corrects these aspects by integrating more surveys, even from the ground. The fact remains that it is convenient to have a flexible and timely parallel procedure, suitable for localized events and with low residence times, available even in the case of the non-activation of CEMS. For this reason, the Italian National Fire Corp has developed a rapid assessment procedure of flooded areas. The widespread diffusion of the Corps assets throughout the territory allows immediate activation due to the direct and trusting attitude citizens naturally have with the Fire Brigade in any calamity. The Fire Corps, using a geographic information system (GIS), creates, manages, and analyzes data related to floods, integrating location data (where things are) with all types of descriptive information (water depth, building damages, search and rescue operations, etc.). This provides a foundation for mapping and analysis to understand flood patterns, citizens' needs, and future planning. The benefits include improved communication and efficiency as well as better management and decision making. The report of substantial flooding of the territory also triggers the take-off of an all-weather helicopter that moves to the disaster site. Once the edge of the flooded area is reached, the helicopter follows its entire length. A GPS device records the track, which is immediately made available via radio. This procedure can be repeated several times during the same event, also providing indications of the dynamics of the flood.

A further class of data reinforces this assessment. Every intervention that the fire brigade teams carry out on the territory is georeferenced with a GPS point. During a flood, the calls are generally many dozen; they counted 640 interventions in three days in this specific case. This punctual information can provide some advice on the intensity of the event and confirm the quality of the assessment. Examples of the raw data directly from GPS tracks and the final result after data processing are respectively reported in Figures 5 and 6.

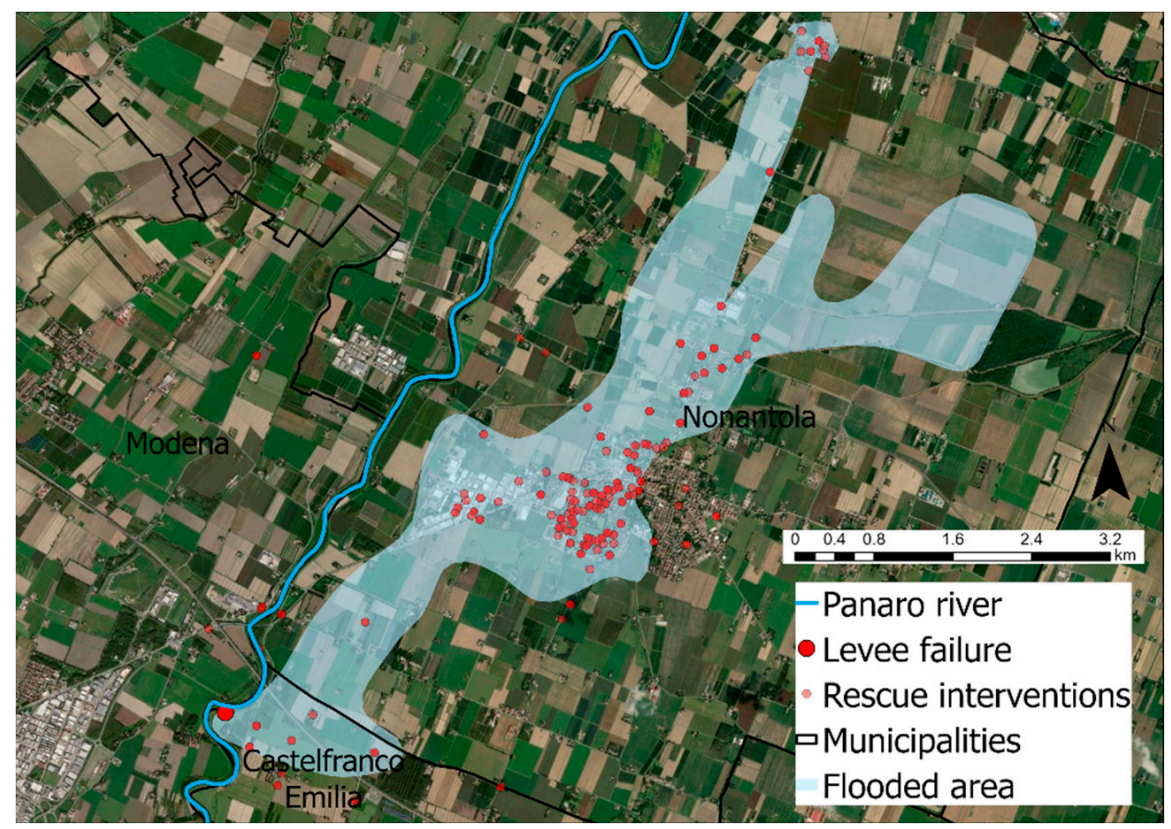

Figure 6. Flooded area obtained after data processing: the perimeter has been obtained from the helicopter and the technical commission surveys, and points represent the interventions of the Fire Corps. 
Once the flooded area $S_{0}$ has been delimited, after a comparison among Copernicus data, Fire Corps mapping, and local verification, we can assess the total flooded buildings ${ }^{\prime}$ footprint area $F_{a}$ by elaborating on statistical data referring to the census areas included in $S_{0}$. In detail, for the analysis, we refer to three census variables that are $S_{r}\left(\mathrm{~m}^{2}\right)$, the surface area of dwellings occupied by at least one resident person, $N_{b}(-)$, the number of residential buildings occupied by at least one resident person, and the group of variables $R_{i}(-)$, the number of dwellings with i-storeys.

For each census area included in the flooded perimeter, we evaluated the total surface $S_{s}\left(\mathrm{~m}^{2}\right)$. The average surface of a floor $M_{f s}\left(\mathrm{~m}^{2}\right)$ was then evaluated (for every census area) as the ratio between the surface area of dwellings occupied by at least one resident person $S_{r}$ and the total number of floors.

$$
M_{f s}=\frac{S_{r}}{\left(\sum_{i=1}^{n} i R_{i}\right)}
$$

where $n$ is the maximum number of floors. We thus obtained the total footprint area $A_{r}$ $\left(\mathrm{m}^{2}\right)$ of residential buildings in each section by multiplying the average surface by the total number of dwellings $N_{b}(-)$. By assuming that each building has just one flooded floor, i.e., the maximum water level on the ground less than $2.50-3.00 \mathrm{~m}, A_{r}$ is actually an estimation of $F_{a}$.

$$
A_{r}=M_{f_{s}} N_{b}
$$

For the section only partially included in the flooded area, we estimated the surface of the flooded building $F_{a}$ proportionally for the partially flooded surface $F_{s}$.

$$
F_{a}=\frac{A_{r} F_{s}}{S_{s}}
$$

\section{Results}

\subsection{Model Calibration on the Po-Venetian Floodplain HA}

As previously explained, the "zero-order" damage model has been calibrated and validated on two different randomly generated damage datasets chosen in the homogeneous area (HA) of the Po-Venetian floodplain. The damage is then expressed by the formula

$$
D=110.47 F_{a}^{0.96}
$$

We show the results of the calibration/validation process in Figure 7, where each point represents a single municipality with the aggregated conventional surface $F_{a}$ and the related claimed damage $D$. The orange line represents the regression line, built on calibration data, on the log-log plane.

We note the "quasi-linear" relationship due to the power-law exponent being close to one. On the other side, the coefficient of the same power-law indicates the specific damage in the order of $110 \mathrm{EUR} / \mathrm{m}^{2}$. The correlation coefficient of the regression is $R^{2}=0.70$. The error distribution analysis is shown in Figure 8. We observe that half of the data stand in the $+/-50 \%$ relative error range.

The same can be observed in the graph in Figure 9 where the distribution of observed versus estimated damages is shown. The green line is the best agreement and points represent the values for those municipalities considered in the validation phase. We observed during the validation that points far from the line are those with a few claims. 


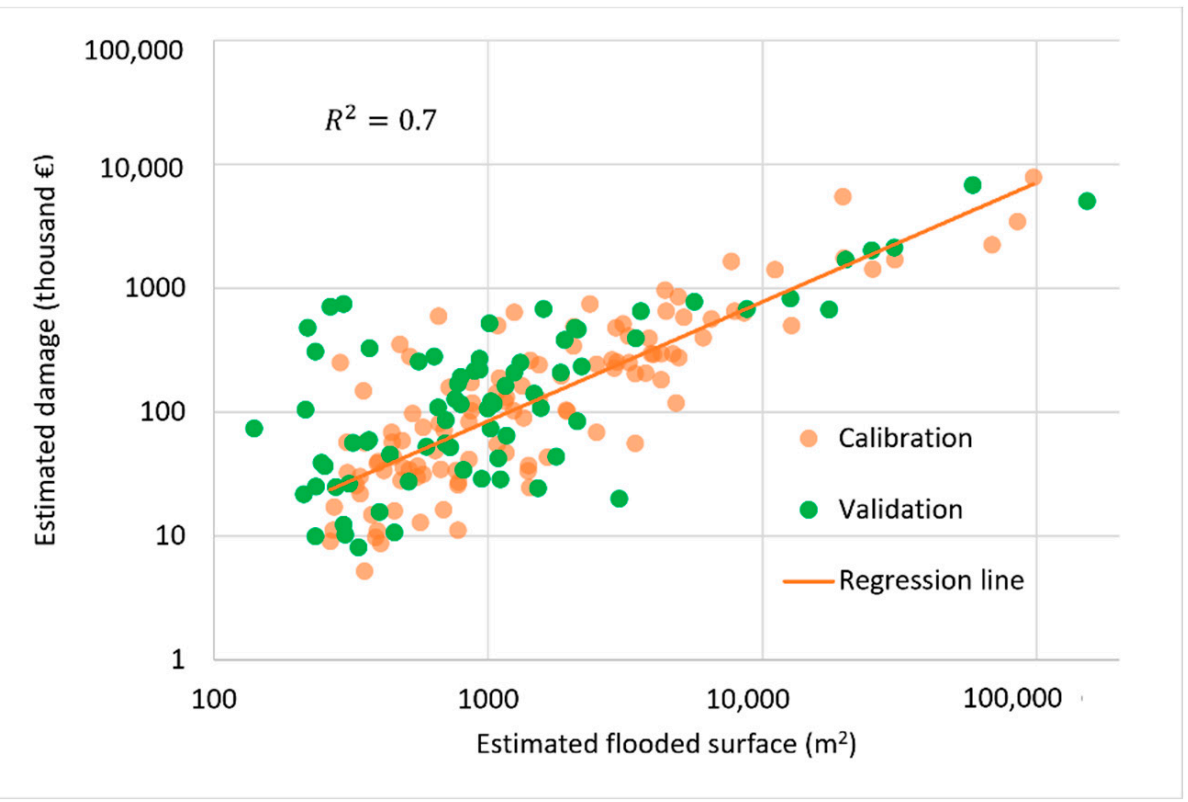

Figure 7. Calibration results. Each point corresponds to data aggregated at the scale of a single municipality. The regression line has been derived from the calibration dataset: the validation dataset fits well the curve.

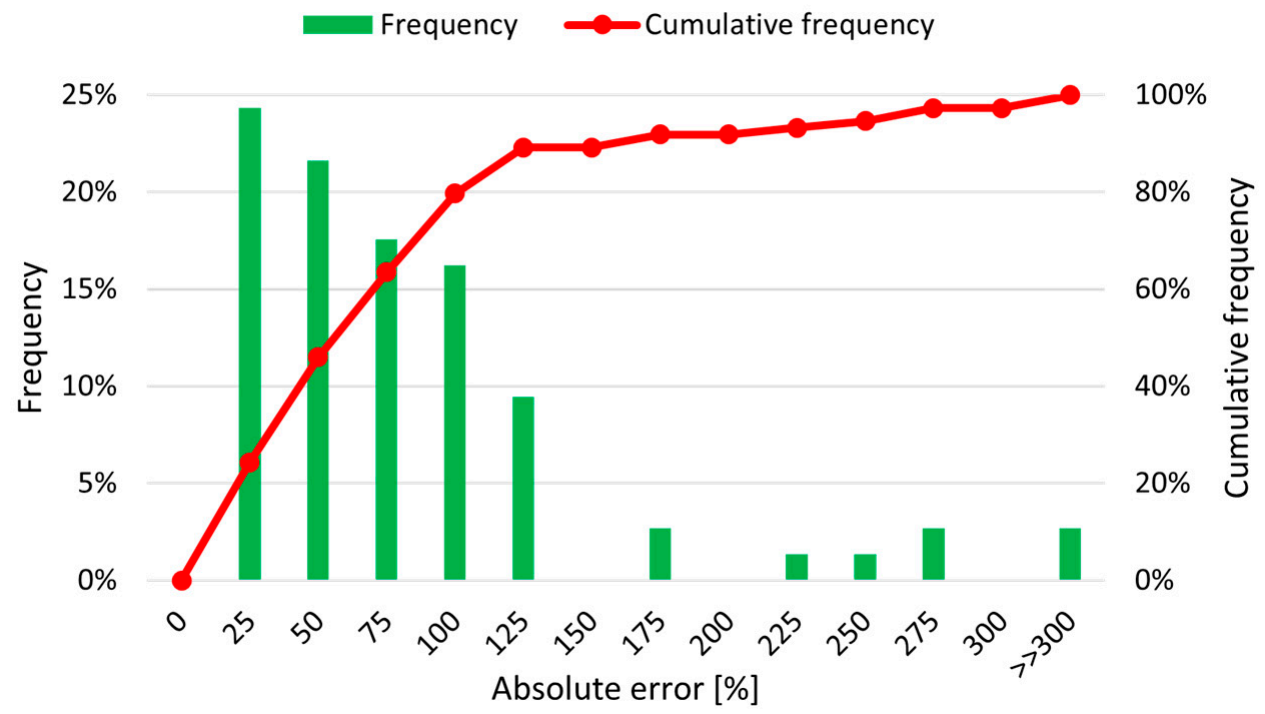

Figure 8. Frequency distribution of the absolute value of percentage error in the validation dataset. Columns represent the percentage of municipalities considered during the validation phase, according to the error classes ( $x$-axis). The red line represents the cumulative error. 


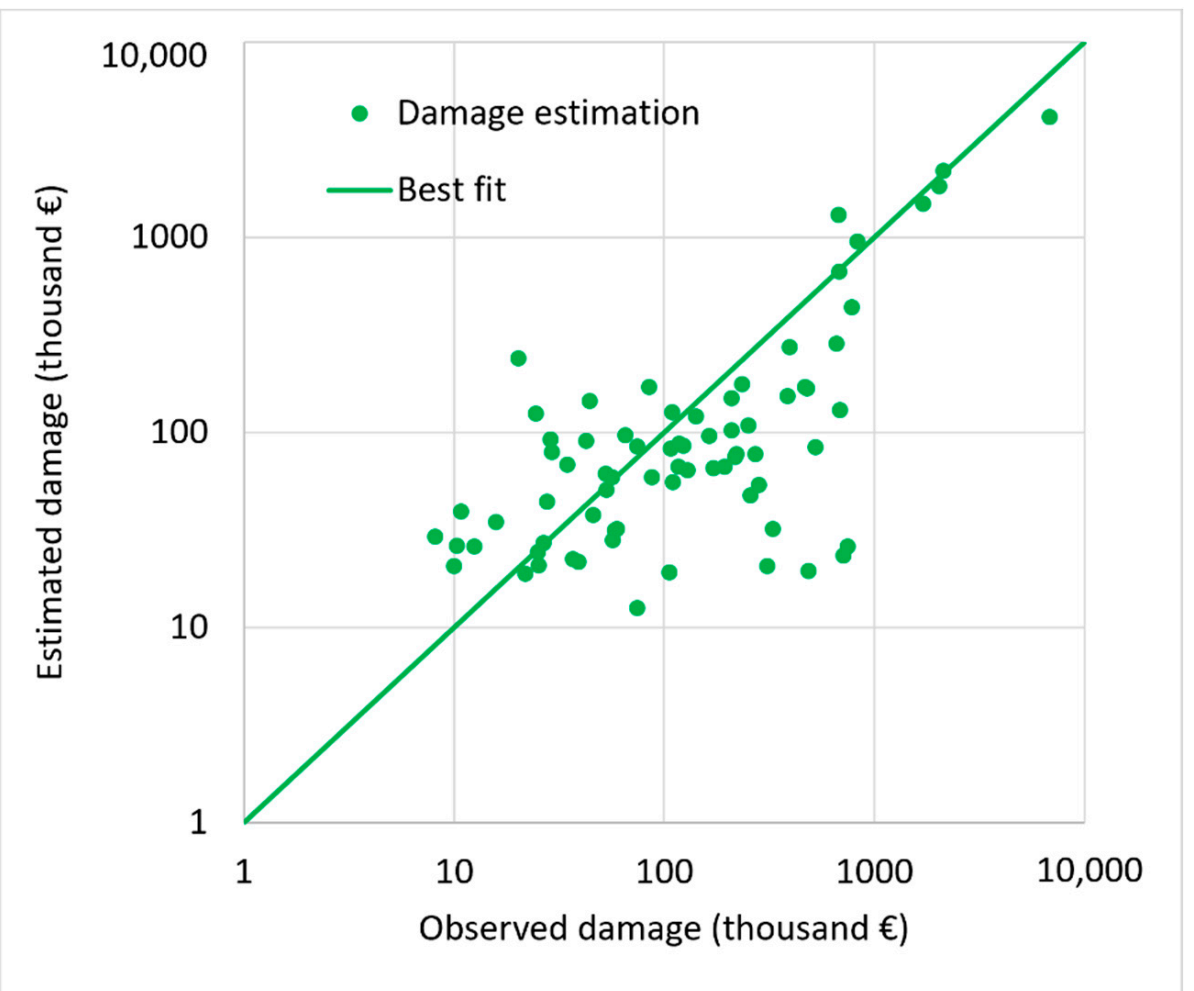

Figure 9. Estimated vs. observed damage for the model validation dataset.

\subsection{Implementation of the Model in Emilia-Romagna December 2020 Flood}

The flooded surface $S_{0}$, at its maximum extension, was estimated around $13 \mathrm{~km}^{2} \mathrm{by}$ the Fire Corps assessment. Further surveys on the ground were performed later on by the municipality that confirmed the estimate. Such an area involves two municipalities, Castelfranco Emilia and Nonantola. For them, we evaluated the flooded residential area (through the method previously described) and finally the expected damage with Equation (5).

Results in terms of the flooded area $F_{a}$, estimated damage $D$, observed damage $D_{0}$ and global relative estimation errors are summarized in Table 2 . It must be noted that Castelfranco Emilia was flooded just over a single census area. The town of Nonantola instead was significantly hit by the event giving rise to a higher characteristic surface area $F_{a}$.

Table 2. Results of the model application.

\begin{tabular}{ccccc}
\hline Municipality & Flooded Area $\boldsymbol{F}_{\boldsymbol{a}}$ & $\begin{array}{c}\text { Estimated } \\
\text { Damage } \boldsymbol{D}\end{array}$ & $\begin{array}{c}\text { Observed } \\
\text { Damage } \boldsymbol{D}_{\boldsymbol{0}}\end{array}$ & Error \\
\hline Castelfranco Emilia & $926.67 \mathrm{~m}^{2}$ & $77,900 \mathrm{EUR}$ & $466,400 \mathrm{EUR}$ & $83 \%$ \\
Nonantola & $367,109.93 \mathrm{~m}^{2}$ & $24,3 \mathrm{MEUR}$ & $48,6 \mathrm{MEUR}$ & $50 \%$ \\
\hline
\end{tabular}

\section{Discussion}

\subsection{Comparison between $H A$}

The first level of reasoning must be devoted to comparing the models derived for the Po-Venetian plan and for the South of Italy that, as previously discussed, can be considered homogeneous areas for flood damage model estimation.

The Po-Venetian plain covers $64,662 \mathrm{~km}^{2}$, while the HA considered in the previous work deals with $84,339 \mathrm{~km}^{2}$. These areas are the mosaics of respectively 3 and 5 regions for which more than one national state of emergency has been declared for flood events in the last decade in several municipalities. Although the surface areas of the two HA are substantially close to each other $(21.5 \%$ and $28.0 \%$ of the entire national territory), 
the two samples are different regarding climatic, demographic, social, and economic characteristics. In essence, all the elements that lead to the production of flood damage are inherently different.

We compare the two case study areas' climates, to underline that the features of the two territories, even though they are in the same country, are completely different. The comparison is carried out by following the usual scheme proposed by W. Köppen [43], adding a few brief notes on the rainfall and temperature regime [44]. As far as the PoVenetian plain is concerned, we can observe both "sub-continental temperate" and mainly the "continental temperate" "Cf" types. The mean annual temperature ranges between $9.5^{\circ} \mathrm{C}$ and $25^{\circ} \mathrm{C}$. The rainfall trend presents a remarkable variability in Italy [45]. The precipitation regime in the HA shows two maximum rain periods in spring and autumn and two minimum periods in summer and winter. Generally, the autumn maximum is prevalent, and severe flood events usually occur in this period [46].

In the Southern Italy HA, we observe a "subtropical temperate" (Cs) in the Ionic, Mediterranean, and Sicily Island coastal strip, marked by quite limited and very irregular rainfall. The mean annual temperature is higher than $17^{\circ} \mathrm{C}$. On the Tyrrhenian side down to Calabria and Apulia, we find the "hot temperate" type, usually characterized by summer droughts (Csa). The mean annual temperature ranges from 14.5 to $16.9{ }^{\circ} \mathrm{C}$. Mainly, the Mediterranean precipitation regime is typical of nearly the whole of Southern Italy, which presents a maximum winter rainfall and a minimum summer rainfall: it affects Sicily, Calabria, and parts of Apulia. Rainfall is more abundant along the Tyrrhenian side, which is open to the west's perturbations, rather than on the Adriatic-Ionian coast. Over the whole of the Southern Italy HA, heavy convective thunderstorms often induce flooding, one of the natural disasters most responsible for damage to the built environment, infrastructures, and loss of lives [47].

The difference between the two HAs under demographic, social, and economic characters is summarized in Table 3: the duality of the Italian macro regions under different points of view is clear, starting, for example, from the productivity per capita values [28]. All data are derived by the National Institute of Statistics data warehouse [48]. Since the analyses are conducted on recent events (in fact, the damage self-declaration's collection in Italy has started with uniform national criteria only in 2013), we here refer to 2011 census data. However, it is also worth noticing that the built environment is developing slowly in Italy, and the built heritage is mainly old [49]. We can observe how the two areas are in fact pretty different from both climatic and demographic points of view.

Table 3. Main demographic, social, and demographic indexes for the case study area.

\begin{tabular}{lccc}
\hline Main Indexes & Po-Venetian Plain & Southern Italy & Relative Difference \\
\hline Surface area $\left(\mathrm{km}^{2}\right)$ & 64,662 & 84,339 & $-23 \%$ \\
Inhabitants $(-)$ & $19,478,791$ & $17,244,202$ & $+13 \%$ \\
Density $\left(\mathrm{km}^{-2}\right)$ & 301 & 204 & $+47 \%$ \\
GDP (millionEUR) & 703,193 & 314,523 & $+124 \%$ \\
Per capita GDP (EUR) & 36,100 & 18,239 & $+98 \%$ \\
Net annual income per & 34,427 & 25,783 & $+34 \%$ \\
family (EUR) & & & \\
\hline
\end{tabular}

Figure 10 compares the empirical curves derived by the model calibration for the two case studies. The power-law parameters are presented in the following Table 4 . It is worth observing that the exponent deriving from the power-law regression is the same, $m=0.96$, for the two case studies. The degree of data dispersion is also absolutely comparable. We can deduce that the quasi-linearity hypothesized for the model between the characteristic surface and the damage constitutes a reasonably robust assumption, independent of the territorial context considered. 


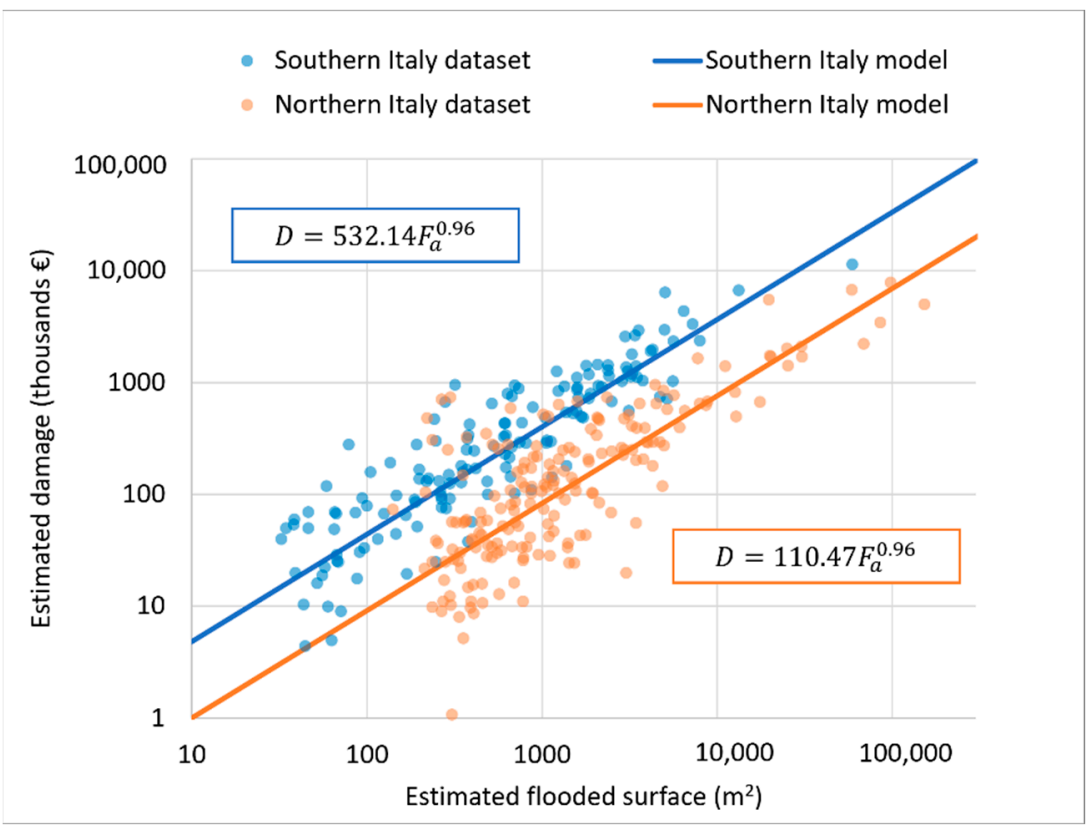

Figure 10. Comparison between the two datasets and models obtained for Northern and Southern Italy.

Table 4. Model power-law parameters.

\begin{tabular}{ccc}
\hline & Po-Venetian Plain & Southern Italy \\
\hline Exponent $(-)$ & 0.96 & 0.96 \\
Coefficient $\left(\right.$ EUR $\left./ \mathrm{m}^{2}\right)$ & 110.47 & 532.14 \\
\hline
\end{tabular}

The same calibration process leads to a specific damage estimate for the Po-Venetian floodplain, nearly equal to one-fifth of that obtained for Southern Italian regions. The following considerations can explain this fact.

In Northern Italy, multi-story buildings are much more diffuse than single-floor houses. ISTAT data are reported in Figure 11. We observe how one-story buildings are around 9\% of the total in the Po-Venetian plain and nearly 30\% in the Southern Italy region. This fact, for a given flood event, is assumed to increase the intensity of the damage.

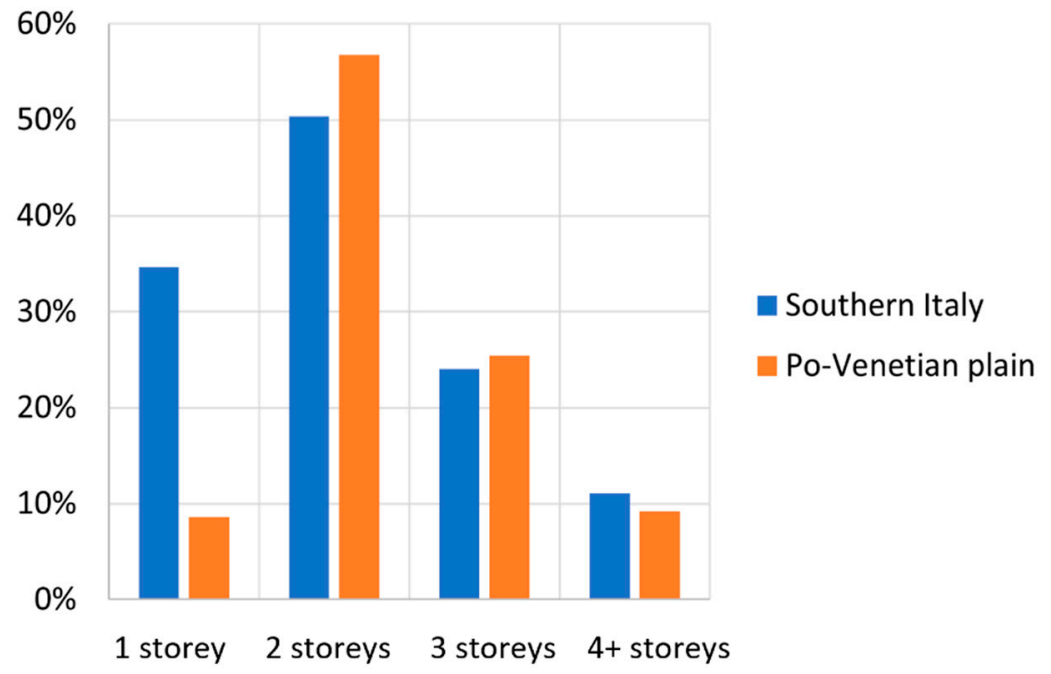

Figure 11. Characteristics of buildings for Po-Venetian floodplain and Southern Italy, obtained from the ISTAT data [31], reworked by the authors. 
A first screening has been performed for both HAs' calibrations to consider just direct inundation from floodplain events. However, the characteristics of flood processes are pretty different in the two HAs. Po-Venetian plain flood processes are typical of extensive plain contexts, with inundation processes very different from those of the Southern Italy basins' typical Apennine and coastal environment valleys. Coastal convective thunderstorms determine most floods in Southern Italy. As noticed before, Mediterranean coastal regions are frequently affected by heavy precipitation events that produce flash floods and landslides [50]. As well as convective rainfall events, most flood processes in the Po-Venetian plain are connected to mesoscale stratiform precipitation patterns, especially relevant for flooding when associated with orographic forcing [51]. This peculiarity, together with the typically flat Padanian landscape, gives rise to different damage-generating phenomena.

A further observation stands in the social vulnerability to natural hazards in Italy $[52,53]$. There is a significant gap between vulnerability in the North of Italy, which is significantly lower than in the South. Although the gap decreases in time [54], the difference remains unfortunately high, enough to explain at least a part of the corresponding gap in specific damage.

\subsection{Discussion of the Results}

The validated model has been applied to the two municipalities most affected by the flood, Nonantola, and Castelfranco Emilia, both located in the region Emilia-Romagna in the province of Modena. The main characteristics of the two municipalities are reported in Table 5.

Table 5. Main characteristics of the case study municipalities.

\begin{tabular}{ccc}
\hline Main Features & Nonantola & Castelfranco Emilia \\
\hline Surface $\left(\mathrm{km}^{2}\right)$ & 55.32 & 102.51 \\
Inhabitants $(-)$ & 16,119 & 33,046 \\
Density $\left(\mathrm{km}^{-2}\right)$ & 291.38 & 322.37 \\
Elevation (m a.s.l.) & 20 & 40 \\
Total residential buildings & 6349 & 15,029 \\
Buildings with 1 floor & 54 & 274 \\
Buildings with 2 floors & 1218 & 2186 \\
Buildings with 3 floors & 919 & 1348 \\
Buildings with 4+ floors & 113 & 552 \\
Classification of degree of urbanization & Town and suburbs & Rural areas \\
Low flood hazard mapping surface $\left(\mathrm{km}^{2}\right)$ & $55.32(100 \%)$ & $102.24(100 \%)$ \\
Medium flood hazard mapping surface $\left(\mathrm{km}^{2}\right)$ & $55.32(100 \%)$ & $102.24(100 \%)$ \\
High flood hazard mapping surface $\left(\mathrm{km}^{2}\right)$ & $8.09(15 \%)$ & $8.19(8 \%)$ \\
\hline
\end{tabular}

The surface of Castelfranco Emilia is almost twice the area of Nonantola, and the same can be said for the number of inhabitants. For this reason, the number of residential buildings is higher in the larger municipality, even though the degree of urbanization is lower. Indeed, Nonantola is a small town with suburbs, while Castelfranco Emilia as a whole, can be seen as a rural area. The entire surface of the two municipalities is included in the delimitation of the medium flood hazard zone identified within the context of the Flood Directive, corresponding to return periods between 500 (low hazard) and 200 years (medium hazard). The "high hazard" zone (20-50 years return period) is instead limited to $8 \%$ of the municipality area in Castelfranco and $15 \%$ in Nonantola. In the specific case study, inundation was due to a levee failure during a lower return period rainfall event even though the ground effects were coherent with the hazard level considered in the mapping.

From the map of Figure 12, we observe that the municipal territory of Castelfranco Emilia was flooded just for a small portion of the total area. Moreover, residential buildings in the flooded area were few and dispersed, and the flood-invested area was mainly crops. From Table 2, we can observe that the model underestimates the observed damage with a 
relatively high error. Actually, the observed damage is made by the sum of only 16 damage claims, two orders of magnitude less than those of Nonantola, thus decreasing the reliability of the model estimation.

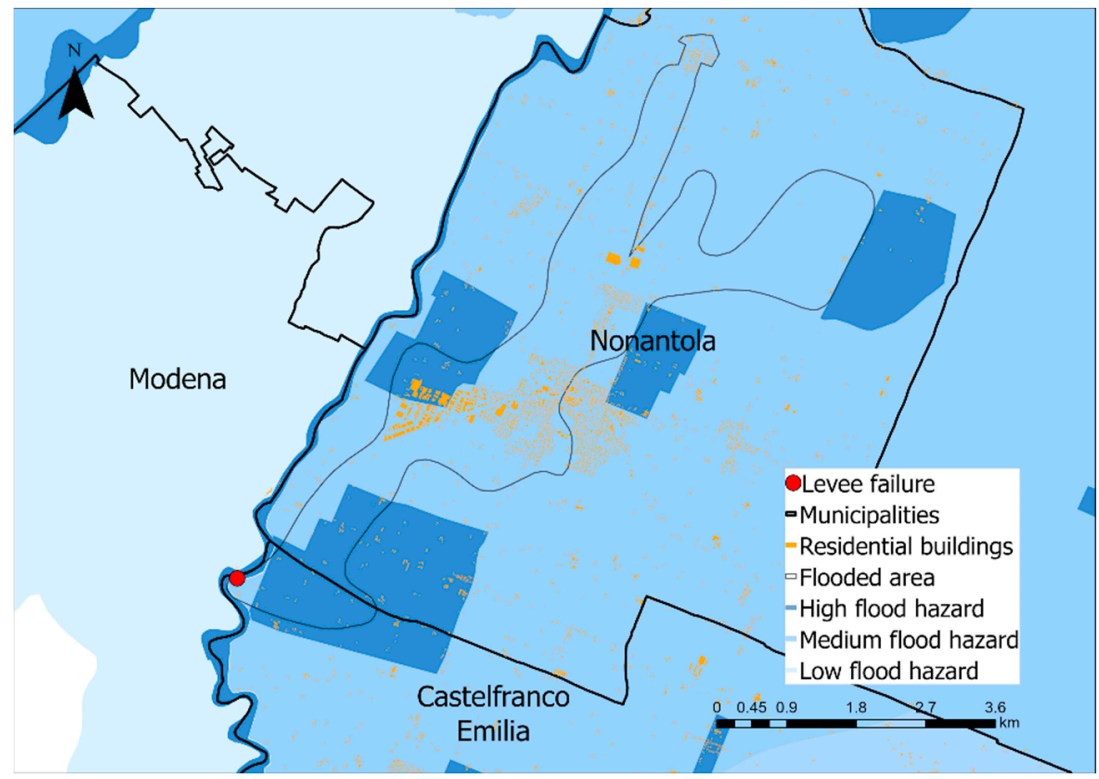

Figure 12. Mapping of the three different flood hazard classes in the study area, and representation of the footprint of the residential buildings inside the flooded surface. The town of Castelfranco Emilia was only in part involved in the flood.

The town of Nonantola and its urban settlement were strongly damaged. The model estimation is much more significant in claims availability, leading to a lower estimation error. In Figure 13, we show the difference between the observed and the estimated values, and the comparison with the calibration dataset.

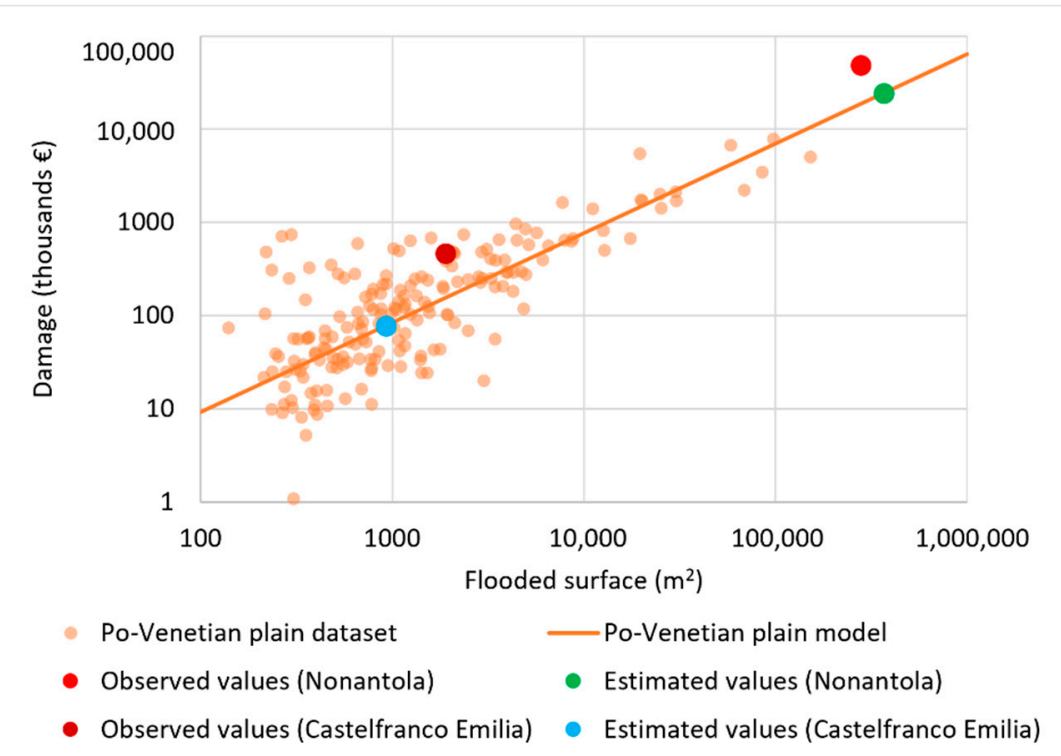

Figure 13. Comparison between observed and estimated damages for the study case.

As in our previous work on South Italy, we can observe that the order of magnitude is the same between the observed and estimated damage (at least for the most significant case), which, even though it may seem to be a rather rough estimate, is in line with results obtained by more sophisticated damage models, which required a level of analysis and an 
amount of time unsuitable for application in the flood's aftermath [25]. This is undoubtedly an encouraging result that further corroborates our intention to implement the model as a quick tool to obtain a first-order estimation of damages.

\section{Conclusions}

We have presented here a procedure for a quick estimate of the damage in the aftermath of a flood event. Private asset damage is considered, while that related to productive activities will be treated in a forthcoming paper. We have discussed the whole assessment cycle, starting from outlining the inundated area down to the economic estimate of the loss. The quick assessment of the flooded area boundaries is performed by low-altitude GPS surveys performed by all-weather capability helicopters. This kind of survey is a standard practice of the Italian National Fire Corps in any significant flood event. GPS tracks once processed and analysed, allow a detailed reconstruction of the flooded perimeter. Sometimes multiple surveys are performed, leading to a view on the inundation process dynamics. This kind of data, integrated into the zero-order flood damage model, allows a near real-time estimation of damages. Such information can contribute, among other things, to addressing the immediate post-emergency management operations and helps policymakers to correctly and promptly allocate financial resources. In the chaos of the postevent, the priorities are to recover the injured, take care of the displaced, and re-establish essential services. There is no time (and frequently no way) for a detailed field damage survey. Even though the methodology may appear quite rough, the results, considering the aims of the model, seem to be promising. However, a direct comparison between the zero-order and the traditional damage curve approach could be interesting and will be carried out in the future.

The "zero-order" method was introduced in a previous paper with a successful application in Southern Italy. With the present work, the model is implemented on the Po-Venetian plain area, which covers more than $20 \%$ of the Italian territory and presents completely different characteristics from climate, morphologic, demographic, social, and economic points of view. Comparing the two case studies confirms that the "zero-order" approach can lead to the first estimate of damages, at least in the order of magnitude. The results are obtained by calibrating a single parameter, given by the specific damage per unit flooded area. In particular, the paper shows how a single calibration can account for estimates on areas of the order of thousands of square kilometers. The calibration process requires a previous detailed analysis at the regional scale to obtain homogeneous areas that can be treated as a unique environment for quick damage estimation.

Author Contributions: Conceptualization, G.M., D.M., A.P. and F.Z.; methodology, L.M., A.P. and F.Z.; software, A.P.; validation, G.M., A.P. and F.Z.; formal analysis, G.M.; investigation, A.P. and F.Z.; resources, L.M.; data curation, A.P. and F.Z.; writing-original draft preparation, A.P., F.Z. and L.M.; writing-review and editing, G.M. and D.M.; supervision, G.M.; project administration, G.M. All authors have read and agreed to the published version of the manuscript.

Funding: This research received no external funding.

Institutional Review Board Statement: Not applicable.

Informed Consent Statement: Not applicable.

Data Availability Statement: Dataset related to this article was kindly provided by Regional Authorities, the Fire Corps, and the National Civil Protection Department, and are available with their permission.

Acknowledgments: This work was carried out within the National Operational Programme on Governance and Institutional Capacity (PON) "Hydraulic and Geo-hydrological risks". The Programme is a 2014-2020 cohesion policy tool funded by the European Union under the European Structural and Investment Funds-ESI Funds. We thank the Italian Civil Protection Department for support in producing data and useful discussion. We would also like to show our gratitude to the Italian 
National Fire Corps for sharing knowledge and best practice. Data made available have been useful to complete the flood damage estimation.

Conflicts of Interest: The authors declare no conflict of interest.

\section{References}

1. Molinari, D.; Menoni, S.; Aronica, G.T.; Ballio, F.; Berni, N.; Pandolfo, C.; Stelluti, M.; Minucci, G. Ex post damage assessment: An Italian experience. Nat. Hazards Earth Syst. Sci. 2014, 14, 901-916. [CrossRef]

2. Meyer, V.; Becker, N.; Markantonis, V.; Schwarze, R.; van den Bergh, J.C.J.M.; Bouwer, L.M.; Bubeck, P.; Ciavola, P.; Genovese, E.; Green, C. Assessing the costs of natural hazards-state of the art and knowledge gaps. Nat. Hazards Earth Syst. Sci. 2013, 13, 1351-1373. [CrossRef]

3. Dottori, F.; Figueiredo, R.; Martina, M.L.V.; Molinari, D.; Scorzini, A.R. INSYDE: A synthetic, probabilistic flood damage model based on explicit cost analysis. Nat. Hazards Earth Syst. Sci. 2016, 16, 2577-2591. [CrossRef]

4. Centre for Research on the Epidemiology of Disaster (CRED) UNISDR. The Human Cost of Natural Disasters: A Global Perspective; Centre for Research on the Epidemiology of Disaster: Brussels, Belgium, 2015.

5. Gerl, T.; Kreibich, H.; Franco, G.; Marechal, D.; Schröter, K. A review of flood loss models as basis for harmonization and benchmarking. PLoS ONE 2016, 11, e0159791. [CrossRef] [PubMed]

6. Scorzini, A.R.; Frank, E. Flood damage curves: New insights from the 2010 flood in Veneto, Italy. J. Flood Risk Manag. 2017, 10, 381-392. [CrossRef]

7. Schröter, K.; Kreibich, H.; Vogel, K.; Riggelsen, C.; Scherbaum, F.; Merz, B. How useful are complex flood damage models? Water Resour. Res. 2014, 50, 3378-3395. [CrossRef]

8. Smith, D.I. Flood damage estimation-A review of urban stage-damage curves and loss functions. Water 1994, 20, $231-238$.

9. Merz, B.; Kreibich, H.; Schwarze, R.; Thieken, A. Review article: Assessment of economic flood damage. Nat. Hazards Earth Syst. Sci. 2010, 10, 1697-1724. [CrossRef]

10. Olesen, L.; Löwe, R.; Arnbjerg-Nielsen, K. Flood Damage Assessment-Literature Review and Recommended Procedure; Cooperative Research Centre for Water Sensitive Cities: Melbourne, Australia, 2017. Available online: https://watersensitivecities.org.au/ content/flood-damage-assessment-literature-review-recommended-procedure/ (accessed on 28 November 2021).

11. Carisi, F.; Schröter, K.; Domeneghetti, A.; Kreibich, H.; Castellarin, A. Development and assessment of uni-and multivariable flood loss models for Emilia-Romagna (Italy). Nat. Hazards Earth Syst. Sci. 2018, 18, 2057-2079. [CrossRef]

12. Luino, F.; Chiarle, M.; Nigrelli, G.; Agangi, A.; Biddoccu, M.; Cirio, C.G.; Giulietto, W. A model for estimating flood damage in Italy: Preliminary results. WIT Trans. Ecol. Environ. 2006, 98, 65-74.

13. Huizinga, J.; De Moel, H.; Szewczyk, W. Global Flood Depth-Damage Functions: Methodology and the Database with Guidelines; Joint Research Centre: Ispra, Italy, 2017.

14. Hammond, M.J.; Chen, A.S.; Djordjević, S.; Butler, D.; Mark, O. Urban flood impact assessment: A state-of-the-art review. Urban Water J. 2015, 12, 14-29. [CrossRef]

15. Cammerer, H.; Thieken, A.H.; Lammel, J. Adaptability and transferability of flood loss functions in residential areas. Nat. Hazards Earth Syst. Sci. 2013, 13, 3063-3081. [CrossRef]

16. Merz, B.; Kreibich, H.; Lall, U. Multi-variate flood damage assessment: A tree-based data-mining approach. Nat. Hazards Earth Syst. Sci. 2013, 13, 53-64. [CrossRef]

17. Arrighi, C.; Brugioni, M.; Castelli, F.; Franceschini, S.; Mazzanti, B. Urban micro-scale flood risk estimation with parsimonious hydraulic modelling and census data. Nat. Hazards Earth Syst. Sci. 2013, 13, 1375-1391. [CrossRef]

18. Albano, R.; Mancusi, L.; Sole, A.; Adamowski, J. Collaborative strategies for sustainable EU flood risk management: FOSS and geospatial tools-Challenges and opportunities for operative risk analysis. ISPRS Int. J. Geo-Inf. 2015, 4, 2704-2727. [CrossRef]

19. Pita, G.L.; Albornoz, B.S.; Zaracho, J.I. Flood depth-damage and fragility functions derived with structured expert judgment. J. Hydrol. 2021, 603, 126982. [CrossRef]

20. Malgwi, M.B.; Schlögl, M.; Keiler, M. Expert-based versus data-driven flood damage models: A comparative evaluation for data-scarce regions. Int. J. Disaster Risk Reduct. 2021, 57, 102148. [CrossRef]

21. Zischg, A.P.; Röthlisberger, V.; Mosimann, M.; Profico-Kaltenrieder, R.; Bresch, D.N.; Fuchs, S.; Kauzlaric, M.; Keiler, M. Evaluating targeted heuristics for vulnerability assessment in flood impact model chains. J. Flood Risk Manag. 2021, 14, e12736. [CrossRef]

22. Pogliani, A.; Bertulessi, M.; Bignami, D.F.; Boschini, I.; Del Vecchio, M.; Menduni, G.; Molinari, D.; Zambrini, F. A Zero-Order Flood Damage Model for Regional-Scale Quick Assessments. Water 2021, 13, 1292. [CrossRef]

23. Ajmar, A.; Boccardo, P.; Borglia, M.; Kucera, J.; Giulio-Tonolo, F.; Wania, A. Response to flood events: The role of satellite-based emergency mapping and the experience of the Copernicus emergency management service. In Flood Damage Survey and Assessment: New Insights from Research and Practice; John Wiley \& Sons: Hoboken, NJ, USA, 2017; pp. 213-228.

24. Voigt, S.; Giulio-Tonolo, F.; Lyons, J.; Kučera, J.; Jones, B.; Schneiderhan, T.; Platzeck, G.; Kaku, K.; Hazarika, M.K.; Czaran, L. Global trends in satellite-based emergency mapping. Science 2016, 353, 247-252. [CrossRef]

25. Molinari, D.; Scorzini, A.R.; Arrighi, C.; Carisi, F.; Castelli, F.; Domeneghetti, A.; Gallazzi, A.; Galliani, M.; Grelot, F.; Kellermann, P. Are flood damage models converging to "reality"? Lessons learnt from a blind test. Nat. Hazards Earth Syst. Sci. 2020, 20, 2997-3017. [CrossRef] 
26. Regione Emilia-Romagna, Ambiente Regione Emilia-Romagna. 9 August 2021. Available online: https://ambiente.regione. emilia-romagna.it/it/notizie/allegati/allegati-2021/prot_02-03-2021_0177836-allegato-ndeg-1-relazione_di_dettaglio_sgn_ -1-_timbrato.pdf (accessed on 28 November 2021).

27. Thieken, A.H.; Müller, M.; Kreibich, H.; Merz, B. Flood damage and influencing factors: New insights from the August 2002 flood in Germany. Water Resour. Res. 2005, 41, W12430. [CrossRef]

28. Felice, E. The roots of a dual equilibrium: GDP, productivity, and structural change in the Italian regions in the long run (1871-2011). Eur. Rev. Econ. Hist. 2019, 23, 499-528.

29. Camarasa-Belmonte, A.M.; Soriano-García, J. Flood risk assessment and mapping in peri-urban Mediterranean environments using hydrogeomorphology. Application to ephemeral streams in the Valencia region (eastern Spain). Landsc. Urban Plan. 2012, 104, 189-200. [CrossRef]

30. Pellegrini, M. The Po valley: Methods of study, geological characteristics and example of geomorphological evolution. In Proceedings of the 15th Plenary Meeting IGU Geomorphological Survey and Mapping, Modena, Italy, 7-15 September 1979; pp. 83-101.

31. Istituto Nazionale di Statistica. Il mercato del lavoro 2019. In Una Lettura Integrata; Istituto Nazionale di Statistica: Rome, Italy, 2020; Volume 16, ISBN 978-88-458-2009-0.

32. Rapoport, A. Spatial organization and the built environment. In Companion Encyclopedia of Anthropology: Humanity, Culture and Social Life; Rouledge: London, UK; New York, NY, USA, 1994; pp. 460-502.

33. Domeneghetti, A.; Carisi, F.; Castellarin, A.; Brath, A. Evolution of flood risk over large areas: Quantitative assessment for the Po river. J. Hydrol. 2015, 527, 809-823. [CrossRef]

34. Masoero, A.; Claps, P.; Asselman, N.E.; Mosselman, E.; Di Baldassarre, G. Reconstruction and analysis of the Po River inundation of 1951. Hydrol. Processes 2012, 27, 1341-1348. [CrossRef]

35. Orlandini, S.; Moretti, G.; Albertson, J.D. Evidence of an emerging levee failure mechanism causing disastrous floods in Italy. Water Resour. Res. 2015, 51, 7995-8011. [CrossRef]

36. Mazzoleni, M.; Bacchi, B.; Barontini, S.; Di Baldassarre, G.P.M.; Ranzi, R. Flooding hazard mapping in floodplain areas affected by piping breaches in the Po river, Italy. J. Hydrol. Eng. 2014, 19, 717-731. [CrossRef]

37. Camuffo, D.; Enzi, S. The analysis of two bi-millennial series: Tiber and Po river floods. In Climatic Variations and Forcing Mechanisms of the Last 2000 Years; Springer: Berlin/Heidelberg, Germany, 1996; pp. 433-450.

38. Istituto Nazionale di Statistica. Atti Del $9^{\circ}$ Censimento Generale Dell'Industria E Dei Servizi E Censimento Delle Istituzioni Non Profit, Le Sezioni Di Censimento; Istituto Nazionale di Statistica: Rome, Italy, 2011.

39. Cacace, F.; Zuccaro, G.; De Gregorio, D.; Perelli, F.L. Building Inventory at National scale by evaluation of seismic vulnerability classes distribution based on Census data analysis: BINC procedure. Int. J. Disaster Risk Reduct. 2018, 28, 384-393. [CrossRef]

40. Notti, D.; Giordan, D.; Caló, F.; Pepe, A.; Zucca, F. Potential and limitations of open satellite data for flood mapping. Remote Sens. 2018, 10, 1673. [CrossRef]

41. Inès, J.-B.; Annett, W.; Simone, D. Manual for CEMS-Rapid Mapping Products; Publications Office of the European Union: Luxembourg, 2020.

42. Rojas, R.; Feyen, L.; Watkiss, P. Climate change and river floods in the European Union: Socio-economic consequences and the costs and benefits of adaptation. Glob. Environ. Chang. 2013, 23, 1737-1751. [CrossRef]

43. Köppen, W. Das geographische system der klimat. Handbuch Der Klimatologie; Gebrüder Borntraeger Verlagsbuchhandlung: Berlin, Germany, 1936; Volume I.

44. Fratianni, S.; Acquaotta, F. The climate of Italy. In Landscapes and Landforms of Italy; Soldati, M., Marchetti, M., Eds.; Springer International Publishing: Berlin/Heidelberg, Germany, 2017; pp. 29-38.

45. Pinna, M.; Vittorini, S. Contributo alla determinazione dei regimi pluviometrici in Italia. Soc. Geogr. Ital. 1989, $39,147-168$.

46. Guzzetti, F.; Cardinali, M.; Reichenbach, P. The AVI Project: A bibliographical and archive inventory of landslides and floods in Italy. Environ. Manag. 1994, 18, 623-633. [CrossRef]

47. Terranova, O.G.; Gariano, S. Rainstorms able to induce flash floods in a Mediterranean-climate region (Calabria, Southern Italy). Nat. Hazards Earth Syst. Sci. 2014, 14, 2423-2434. [CrossRef]

48. Istituto Nazionale di Statistica. Censimento della Popolazione e delle Abitazioni; Istituto Nazionale di Statistica: Rome, Italy, 2011.

49. Istituto Nazionale di Statistica. Costruzioni, Censimento ISTAT; Istituto Nazionale di Statistica: Rome, Italy, 2011.

50. Lee, K.; Flamant, C.; Ducrocq, V.; Duffourg, F.; Fourrié, N.D.S. Convective initiation and maintenance processes of two backbuilding mesoscale convective systems leading to heavy precipitation events in Southern Italy during HyMeX IOP 13. Q. J. R. Meteorol. Soc. 2016, 142, 2623-2635. [CrossRef]

51. Buzzi, A.; Foschini, L. Mesoscale Meteorological Features Associated with Heavy Precipitation in the Southern Alpine Region. Meteorol. Atmos. Phys. 2000, 72, 131-146. [CrossRef]

52. Frigerio, I.; De Amicis, M. Mapping social vulnerability to natural hazards in Italy: A suitable tool for risk mitigation strategies. Environ. Sci. Policy 2016, 63, 187-196. [CrossRef]

53. Bignami, D.F.; Dragoni, A.; Menduni, G. Assessing and improving flood and landslide community social awareness and engagement via a web platform: The case of Italy. Int. J. Disaster Risk Sci. 2018, 9, 530-540. [CrossRef]

54. Frigerio, I.; Carnelli, F.; Cabinio, M.; De Amicis, M. Spatiotemporal pattern of social vulnerability in Italy. Int. J. Disaster Risk Sci. 2018, 9, 249-262. [CrossRef] 